1. FCPS

Assistant Professor Non-Invasive Cardiology

National Institute of Cardiovascular Disease (NICVD), Karachi.

2. FCPS

Senior Registor Non-Invasive Cardiology

National Institute of Cardiovascular Disease (NICVD), Karachi.

3. FCPS

Senior Registor Non-Invasive Cardiology

National Institute of Cardiovascular Disease (NICVD), Karachi.

4. FCPS

Assistant Professor Non-Invasive Cardiology

National Institute of Cardiovascular Disease (NICVD), Karachi.

5. FCPS

Senior Registor Non-Invasive Cardiology

National Institute of Cardiovascular Disease (NICVD), Karachi.

6. FCPS

Fellow in Electrophysiology National Institute of Cardiovascular Disease (NICVD), Karachi.

Correspondence Address:

Dr. Lubna Baqai

Department of Nnon-Interventional

Cardiology

National Institute of Cadiovascular

Disease (NICVD), Karachi.

dr.I_baqai@yahoo.com

Article received on:

22/09/2020

Accepted for publication:

12/02/2021

\section{Tricupsid valve involvement in chronic rheumatic mitral stenosis: An observational study.}

\begin{abstract}
Lubna Baqai ${ }^{1}$, Shazia Rasheed ${ }^{2}$, Naveen Nasim $^{3}$, Irum Jehan Balouch ${ }^{4}$, Sumiya Gurmani $^{5}$,
\end{abstract} Ghulam Kubra ${ }^{6}$

ABSTRACT... Objective: The aim of this study was to assess the incidence of tricuspid valve involvement in rheumatic mitral stenosis among Pakistani patients that helps in the medical decisions and special consideration for the management of disease. Study Design: Prospective Study. Setting: National Institute of Cardiovascular Disease (NICVD), Karachi. Period: February 2018 to November 2019. Material \& Methods: As per the study inclusion criteria, Three fifty eight (358) Pakistani patients' diagnosed with Rheumatic Mitral stenosis. The study was compiled as per international standards (ICH-GCP-E6), prior to initiation, the ethics review committee approved the study and informed consent was taken from all recruited subjects. Results: The study prospectively assessed the echocardiographic profile of rheumatic heart disease patients and recruited 358 patients with chronic Rheumatic Mitral Stenosis. Out of these patients, 93.9\% (336) had tricuspid regurgitation and 7\% (25) had triscuspid stenosis. Their ages ranged from 14 to 85 years (mean 40.3 years). Of these, $73.6 \%$ (263) were females and $26.5 \%(95)$ were males. On the basis of severity, in case of tricuspid stenosis, 3.9\% (14) were mild, $1.1 \%$ (4) were moderate and $2 \%$ (7) were progress from mild to moderate. In case of Tricuspid regurgitation, $42.5 \%$ (143) were mild, 31.2\% (105) moderate and $26.1 \%$ (88) were severe. Conclusion: The study concluded that in the local population, the patients with chronic Rheumatic Mitral Stenosis had common involvement of Triscuspid valvular disease, more come in female and affected all age groups. Hence, before management of Rheumatic Mitral Stenosis with other lesions, especially the Triscuspid valve involvement, detailed assessment is required in order to achieve the best outcome in patients with the Mitral valve disease.

Key words: $\quad$ Pakistani Population, Rheumatic Mitral Stenosis, Triscuspid Valve Disease.

Article Citation: Baqai L, Rasheed S, Nasim N, Balouch IJ, Gurmani S, Kubra G. Tricupsid valve involvement in chronic rheumatic mitral stenosis: An observational study. Professional Med J 2021; 28(9):1315-1321. https://doi.org/10.29309/TPMJ/2021.28.09.6100

\section{INTRODUCTION}

Rheumatic Heart Disease (RHD) continues to impose a significant health burden across the globe. ${ }^{1}$ As per disease global prevalence, at least 33.4 million individuals were affected with RHD, around 10.5 million were lifetime disabled and 319,400 deaths attributed to RHD. ${ }^{1}$ In developing countries, the RHD contributed to the significant morbidity and mortality and the incidence is highest in Oceania, central sub-Saharan Africa, and South Asia. ${ }^{2}$ In Pakistan, the prevalence of RHD in the rural community affected between 12 per 1000 people and prominent cause of premature death and disability. ${ }^{3}$ The RHD may affect any cardiac valve, however, left sided heart is the most affected region and frequently involved the mitral valve. ${ }^{4}$ The mitral stenosis (MS) is most prevalent isolated valvular heart disease in developing countries. ${ }^{5}$ The Mitral stenosis can lead to many cardiovascular complications, including the involvement of tricuspid value disease. ${ }^{6}$ The Tricuspid valve stenosis is relatively a rare condition and is usually accompanied by mitral stenosis. ${ }^{7,8}$ The condition is almost always related to rheumatic disease, may also associated with other rare conditions like endocarditis, Lupus erythematous, right atrial myoma, endomyocardial fibrosis and congenital tricuspid atresia. ${ }^{9}$ Tricuspid stenosis can exist as a congenital lesion or present later in the life with other conditions. ${ }^{10}$ Although, the contribution of the tricuspid valve is well recognized in Rheumatic 
patients, still the disorders of right-sided cardiac valves attract less attention than left-sided valves. ${ }^{7,10,11}$ Generally, the rheumatic tricuspid valve disease is commonly missed during routine clinical examination exception being advanced cases with a high degree of clinical suspicion..$^{711,12}$ The several studies reported that during autopsies, the tricuspid disease was present in $22-44 \%$ of the cases of RHD. ${ }^{11,13}$ Even during routine cardiac catheterization, tricuspid stenosis can easily be missed so less is studied and more rarely described. ${ }^{14}$ Different studies have analysed the results that unobserved and uncorrected lesions increase perioperative mortality and of morbidity and, following surgical correction of Mitral valvular lesions, may lead to worsen the prognosis that altering the treatment options followed by long term outcomes and complications even after surgical treatment of rheumatic mitral stenosis. ${ }^{6}$ Therefore, as the tricuspid valve pathogenesis is remain complex, and challenge to manage, however the early recognition and appropriate treatment of Triscuspid disease may improve the long-term functional outcome.

In Pakistan, multiple studies were conducted on Rheumatic heart disease, , $^{3,9,11,15-21}$ however, very few studies ${ }^{22,23}$ were described and studied the association of Tricuspid Mitral stenosis with tricuspid valvular disease among Pakistani patients. The aim of the current study was to assess the presence of tricuspid valve disease, its severity and associated clinical factors in patient with chronic rheumatic mitral stenosis with local Pakistani population.

\section{MATERIAL \& METHODS}

It was a single-centre, prospective, hospital based study conducted at the National Institute of Cardiovascular Disease (NICVD), Karachi. As per the study inclusion criteria, three fifty three (358) Pakistani patients' diagnosed with chronic Rheumatic Mitral were recruited from the period of February 2018 to November 2019. The study was compiled as per international standards (ICH-GCP-E6), prior to initiation, the ethics review committee approved the study (ERC-10/2019) and informed consent was taken from all recruited subjects.

\section{Data Collection Procedure}

Inclusion criteria for the study were either gender, age between 18 to 80 years, underwent transthoracic echocardiography, and diagnosed with Chronic Rheumatic Mitral Stenosis. Patients' demographic characteristics, clinical history, indications for the procedure, and echocardiographic diagnoses such as, severity of MS, tricuspid valve involvement and type, tricuspid stenosis and severity, tricuspid regurgitation and severity, and pulmonary hypertension and severity, will be obtained using a structured questionnaire. Patient related information will be kept secured and no personal level information will be disclosed during all the stages of dissemination of the study finding.

\section{Operational Definitions ${ }^{24}$}

\section{Mitral Stenosis (MS)}

MS will be defined based on Transthoracic Echocardiogram (TTE), the mitral leaflet tips become calcified and thickened. A characteristic "hockey stick" appearance of the anterior mitral leaflet is seen. Mitral stenosis is categorized as mild, moderate or severe. The parameters associated with the severity is summarized below.

\section{Pressure Gradient (mmHg) Mitral Valve Area $\left(\mathrm{cm}^{2}\right)$ \\ Norma \\ Mild \\ 0 \\ 1-5 \\ $>4.0$ \\ Moderate \\ 6-10 \\ Severe \\ $>10$ \\ 2.5-4.0 \\ 1.0-1.5 \\ $<2.0$}

\section{Tricuspid Valve Involvement}

Severe tricuspid stenosis will be defined by a Doppler mean pressure gradient $>5 \mathrm{~mm} \mathrm{Hg}$, pressure half-time $\geq 190 \mathrm{~ms}$, or valve area $\leq 1.0$ $\mathrm{cm}^{2}$. And will be classified as mild, moderate, and severe

\section{Tricuspid Regurgitation}

will be measured based on echocardiography and severity will be measured according to the regurgitant jet area with;

- Mild $=<5 \mathrm{~cm}^{2}$

- Moderate $=5-10 \mathrm{~cm}^{2}$

- Severe $=>10 \mathrm{~cm}^{2}$ 
Statistical package for social sciences (SPSS 21) will be used for the analysis of baseline characteristics. Shapiro-Wilk test will be applied to check the hypothesis of normality for quantitative (continuous) variables. Descriptive statistics such as mean \pm SD, median (IQR), skewness, maximum and minimum will be calculated for quantitative (continuous) variables. Frequency and percentages will be calculated for categorical variables. For between the group comparison of quantitative (continuous) variables, t-test will be employed and in case quantitative (continuous) variables fail to comply with the normality assumption Mann-Whitney $U$ test will be used. Chi-square test or fisher exact test will be performed to evaluate the effect of effect modifiers (confounding variables) on study outcome. A two-sided $p$-value $\leq 0.05$ will be taken as criteria for significance.

\section{RESULTS}

Asperstudy results on based of echocardiographic profile, 358 patients with Rheumatic Mitral Stenosis were recruited. Out of these patients, $93.9 \%$ (336) had tricuspid regurgitation and $7 \%$ (25) had triscuspid stenosis. The ages ranged from 14 to 85 years (mean 40.3 years). Of these, $73.6 \%$ (263) were females and $26.5 \%$ (95) were males. The details for involvement of Mitral valvular lesion and associated lesions in Table-l.

As per study results and compare the involvement and its severity of Mitral stenosis and other lesions. The females (6.8\%) wre more affected than male $(4.2 \%)$. For MS, the severity is higher with TR (100) followed by MR (96.4\%) whereas for TS the severity is associated with MS (6.1\%). The details of rest of the lesions in Table-II.

To compare the differences between age, PA pressure and lesions with Mitral stenosis, the details mentioned in Table-III.

If we specifically compare the TS with MS and the differences in terms of Age and PA pressure, the details mentioned in Table-IV.

\begin{tabular}{|c|c|c|c|}
\hline \multicolumn{2}{|c|}{ Variables } & \multicolumn{2}{|c|}{ Frequency (\%) } \\
\hline \multicolumn{2}{|c|}{ Age (Mean and Range) } & \multicolumn{2}{|c|}{$(40.3 \pm 12.2 y r s) 14$ to 85} \\
\hline \multicolumn{4}{|l|}{ Gender } \\
\hline \multicolumn{2}{|l|}{ Male } & \multicolumn{2}{|l|}{$95(26.5)$} \\
\hline \multicolumn{2}{|l|}{ Female } & \multicolumn{2}{|l|}{ 263(73.5) } \\
\hline \multicolumn{4}{|c|}{ Mitral Stenosis (MS) } \\
\hline \multicolumn{2}{|l|}{ No } & \multicolumn{2}{|l|}{0} \\
\hline \multicolumn{2}{|l|}{ Yes } & \multicolumn{2}{|c|}{$358(100 \%)$} \\
\hline \multicolumn{4}{|l|}{ Mitral Regurgitation } \\
\hline \multicolumn{2}{|l|}{ No } & \multicolumn{2}{|l|}{$92(25.7)$} \\
\hline \multicolumn{2}{|l|}{ Yes } & \multicolumn{2}{|l|}{$266(74.3)$} \\
\hline \multicolumn{4}{|l|}{ Tricuspid Stenosis } \\
\hline No & & $333(93)$ & \\
\hline Yes & & $25(7)$ & \\
\hline Tricuspid Regurgi & tion & & \\
\hline No & & $22(6.1)$ & \\
\hline Yes & & $336(93.9)$ & \\
\hline Aortic Stenosis & & & \\
\hline No & & $259(71)$ & \\
\hline Yes & & 104(29) & \\
\hline Aortic Regurgiatai & & & \\
\hline No & & $236(66)$ & \\
\hline Yes & & $123(34)$ & \\
\hline Pulmonary Arteria & lypertensi & ion & \\
\hline No & & $50(14)$ & \\
\hline Yes & & $308(86)$ & \\
\hline $\begin{array}{r}\text { Table-I. Frequency } \\
\text { M }\end{array}$ & $\begin{array}{l}\text { f valvular } \\
\text { al valve st }\end{array}$ & $\begin{array}{l}\text { lesions associa } \\
\text { tenosis. }\end{array}$ & ed with \\
\hline Valvular Disease & $\begin{array}{c}\text { Mitral } \\
\text { Stenosis }\end{array}$ & $\begin{array}{l}\text { Tricuspid } \\
\text { Stenosis }\end{array}$ & $\begin{array}{c}\text { P- } \\
\text { Value }\end{array}$ \\
\hline Variables & & & \\
\hline Gender & $\mathrm{n}(\%)$ & $\mathrm{n}(\%)$ & \\
\hline Male & $4(4.2)$ & $91(95.8)$ & 0.36 \\
\hline Female & $18(6.8)$ & $245(93.2)$ & \\
\hline MS_Severity & & & \\
\hline Mild̄ & $0(0)$ & $18(100)$ & \\
\hline Moderate & $4(10.3)$ & $35(89.7)$ & 0.321 \\
\hline Severe & $18(6.1)$ & 276(73.9) & \\
\hline MR_Severity & & & \\
\hline Mild̄ & $8(8.1)$ & $91(91.9)$ & \\
\hline Moderate & $1(2)$ & 48(98) & 0.532 \\
\hline Severe & $2(3.6)$ & $53(96.4)$ & \\
\hline Mild & $2(7.1)$ & $26(92.9)$ & \\
\hline Moderate & $1(3.6)$ & $27(96.4)$ & \\
\hline TR_Severity & & & \\
\hline Mild & $0(0)$ & $143(42.5 \%)$ & $<.001$ \\
\hline Moderate & $0(0)$ & $105(31.2 \%)$ & \\
\hline Severe & $0(0)$ & $88(26.1 \%)$ & \\
\hline AS_Severity & & & \\
\hline Mild & $3(6.4)$ & $44(93.6)$ & 0.53 \\
\hline Moderate & $1(4.3)$ & $22(95.7)$ & \\
\hline Severe & $4(11.8)$ & $30(88.2)$ & \\
\hline AR_Severity & & & \\
\hline Mild & $7(10)$ & $63(90)$ & \\
\hline Moderate & $1(3.3)$ & $29(96.7)$ & 0.641 \\
\hline Severe & $1(14.3)$ & $6(85.7)$ & \\
\hline Mild To Moderate & $1(6.3)$ & $15(93.8)$ & \\
\hline
\end{tabular}




\begin{tabular}{|l|c|c|c|c|c|c|}
\hline \multicolumn{1}{|c|}{ Variables } & N & Mean & Std. Deviation & Minimum & Maximum & Median \\
\hline Age & 358 & 40.3492 & 12.19558 & 14 & 85.00 \\
\hline PA_Pressure & 325 & 57.2892 & 19.65731 & 25 & 120 \\
\hline Mitral Stenosis & 358 & 0.0698 & 0.25522 & 0 & 1 & .000 \\
\hline
\end{tabular}

Table-III. Mann-Whitney Test, Descriptive details for Mitral Stenosis.

\begin{tabular}{|l|c|c|c|c|}
\hline & Tricuspid Stenosis & N & Mean Rank & Sum of Ranks \\
\hline \multirow{3}{*}{ Age } & No & 333 & 181.63 & 60482.5 \\
\cline { 2 - 5 } & Yes & 25 & 151.14 & 3778.5 \\
\hline Pulmonalue \\
\cline { 2 - 5 }
\end{tabular}

Table-IV. Mann-Whitney Test, Descriptive details for Mitral Stenosis and involvement of TS. $P$ value $\leq 0.05$ Significant

\section{DISCUSSION}

Rheumatic heart disease with an association of valvular disease endures to be a significant disease entity in developing countries including Pakistan. ${ }^{1,2}$ The local population data of 2004 from the National Institute of Cardiovascular Disease, NICVD), the country leading tertiary care hospital, managing the cardiovascular cases reported, 8\%$29 \%$ admissions and $62 \%$ of the surgical procedure is attributable to RHD. ${ }^{25}$ The present study was undertaken at the same study site (NICVD) with an aim to systematically analyse the incidence of Rheumatic Mitral stenosis Pakistani patients with the involvement of Triscuspid valvular disease in the light of Echocardiographic examinations. Globally, the Rheumatic mitral stenosis with the involvement of tricuspid valvular disease is well recognized. 5,6 In Pakistan, previously multiple local studies and surveys addressed the overall patterns of RHD and association of different valvular disease, based on the examination of local communities or frequency and incidence in the hospital settings. ${ }^{3,9,11,15-23}$ The Fahim et al (2007) study results on $3060 \mathrm{RHD}$ patients showed that $70 \%$ patients affected by MS followed by MR in $58.59 \%$ cases. ${ }^{23}$ Similarly, the screening study by MA Shaikh et al on valvular lesions on 100 RHD patients, reported mitral stenosis (MS, 48\%), followed by mitral regurgitation (MR, 42\%). ${ }^{17}$ Another small sample of study on $34 \mathrm{MS}$ patients by Rehan et al (2016) revealed that 22 (62.85\%) MS patients were accompanied with TR. ${ }^{8}$ The retrospective study by Aurakzai et al (2009) screened 13,414 patients with RHD patients, the mixed mitral valve disease was seen in 3,185
$(23.7 \%){ }^{22}$

Overall, our current study results endorsed the past studies both local and international studies, as in 358 Pakistani patients with Rheumatic Mitral Stenosis, the association the Triscuspid valvular disease was not uncommon and the combined MS with TR was $93.3 \%$ (336) with moderate to severe in $41.1 \%$ patients followed by TS of $7 \%$ (25) with severe in $20 \%$ of patients on echocardiographic examination. The TR is commonly exist in MV disease and shared one-third of the patients with mitral stenosis ${ }^{5,6}$. Clinically severe TR has been reported in $23 \%$ to $37 \%$ RHD patients. ${ }^{7,8}$ In our study, the patients Rheumatic Mitral Stenosis with moderate to severe TR were $41.1 \%$ patients. In past study reported the incidence of moderate or severe TR in RHD patients is even higher $(68 \%) .{ }^{8}$ In case of combined MS with TS, globally, only $3 \%$ of TS exists, more commonly in women and usually with the Rheumatic mitral stenosis. ${ }^{7,8,10}$ The congenital form is the rare lesion of TS, only contributed the $0.3 \%$ of all valvular lesions occurring primarily in association with mitral stenosis. ${ }^{10}$ In our study, $72 \%{ }^{18}$ female observed TS in combination with rheumatic mitral stenosis (7\%) and Tricuspid regurgitation.

For the gender distribution of RHD, in majority of the past study data from local and international studies, RHD tends to be more likely and predominance among females, however its cause is unclear. ${ }^{26,27}$ The multiple factors leading to difference in the gender RHD prevalence including social factors (such as child caring might 
exposed repeatedly to group A streptococcus), genetically-mediated immunological factors that predispose an autoimmune responses or often during pregnancy due to the high cardiac burden. ${ }^{4}$ The majority of the local studies in past also reported the high rates of RHD among females with Abrar A et al $(66.6 \%)^{21}$, Faheem et al. $(58.2 \%)^{23}$, Rizvi S et al $(53 \%)^{3}$, Ahmed R et al $(77 \%)^{8}$ among females predominance with RHD. Contrary, the study by Aurakzai et al had male (46\%) predominance for reported RHD. ${ }^{22}$ In our study the female prevalence were very high as female patients with Rheumatic Mitral Stenosis and involvement of Tricuspid valvular disease were $73.5 \%$ as compared to males (26.5\%).

In RHD patients, the multiple valvular disease is a common condition, occurs in $51 \%$ of Rheumatic patients and often associated with graver prognosis and requires specialized therapeutic challenges. ${ }^{28}$ The severity of the multiple value disease based on the specific combination of valve lesions. ${ }^{28}$ In our study, the patients with rheumatic mitral stenosis presented with at least one severe valvular lesion $(24 \%, n=89)$ and TR was the most prevalent of these $(n=336$, 93.9\%). Overall, the patients with Rheumatic mitral stenosis, $3 \%(n=9)$ were presented with the involvement of five valvular lesions and all were found to be severe in nature. The database of American Society of Thoracic Surgeons $(n=$ 290000 patients) from period from 2003 and 2007, $11 \%$ had double valve disease, mainly aortic and mitral, and only $1 \%$ had triple valure disease. ${ }^{29}$ Another Swedish study reported $11 \%$ patients with multiple Valvular disease mainly associated with aortic stenosis (AS) plus aortic regurgitation (AR), AS plus mitral regurgitation (MR) and AR plus MR. ${ }^{30}$

In Beaton et al study $(n=301)$, in RHD patients at least one valvular lesion with MR as the most prevalent of valvular disease (275 out of 301). ${ }^{31}$ Majority of the patient with MS and 22 RHD patients with severe MS and only 4 had severe MR. ${ }^{31}$ It was reported earlier that cases with severe MS were unlikely to have severe MR and were small in numbe. ${ }^{32}$ However, the previously reported study data showned that the cases with severe TR may also associated with other severe valvular lesions (either MR, MS or AR) and with pulmonary hypertension. ${ }^{33}$ The Rashid etal study also described the pattern and extent of tricuspid valve involvement in chronic rheumatic heart disease. ${ }^{7}$ The total of 173 patients with rheumatic heart disease patients, $21 \%(n=36)$ patients had rheumatic tricuspid regurgitation and $41.6 \%(n=$ 15) were associated with tricuspid stenosis. ${ }^{7}$ In our study, $91 \%$ of cases of Trisuspid regurgitaion with Rheumatic Mitral Stenosis and $26 \%$ of cases were severe in nature and $82 \%$ were pulmonary hypertension (Secondary, 82\% \& Primary, 9\%). The severe Trisuspid regurgitaion with MS was associated with other lesion (MR, 69\%, TS, 13\%, AS, $20 \%$, AR ,32\%). Overall, in our study results, the TR is the most common associated $(n=336$, $93.9 \%$ ) valular disease and exclusively seen in association with Rheumatic MS whereas, 7\% $(n=25)$ of patients were presence of tricuspid stenosis in chronic rheumatic mitral stenosis.

The data presented are derived from a single center of the leading tertiary care hospital of largest city of Pakistan managing RHD, however, the data may not reflect the circumstances of other institutes specializing in the management of patients with RHD. Furthermore, the data was acquired in the setting of an observational prospective setup in the routine practice from clinical data and echocardiographic reports, which in some cases may not be as detailed as would be desirable. However, the data collected reflect the actual profiles of patients with $R H D$ in routine practice in the tertiary hospital.

\section{CONCLUSION}

The study concluded that in the local population, the patients with chronic Rheumatic Mitral Stenosis had common involvement of Triscuspid valvular disease mainly TR, more come in female and affected all age groups. Therefore, before management (surgery), the detailed assessment is required especially Triscuspid value involvement in order achieved the better outcome in RHD patient with Mitral valve disease.

Copyright $(12$ Feb, 2021. 


\section{REFERENCES}

1. Abul-Fadl AM, Mourad MM, Ghamrawy A, Sarhan AE. Trends in deaths from rheumatic heart disease in the eastern mediterranean region: Burden and challenges. Journal of cardiovascular development and disease. 2018; 5(2):32.

2. Roth GA, Johnson C, Abajobir A, Abd-Allah F, Abera SF, Abyu $G$, et al. Global, regional, and national burden of cardiovascular diseases for 10 causes, 1990 to 2015. Journal of the American College of Cardiology. 2017; $70(1): 1-25$.

3. Rizvi S, Khan M, Kundi A, Marsh D, Samad A, Pasha O. Status of rheumatic heart disease in rural Pakistan. Heart. 2004; 90(4):394-9.

4. Carapetis JR, Beaton A, Cunningham MW, Guilherme L, Karthikeyan G, Mayosi BM, et al. Acute rheumatic fever and rheumatic heart disease. Nature reviews Disease primers. 2016; 2(1):1-24.

5. Ranjan R, Pressman GS. Aetiology and epidemiology of mitral stenosis. E-Journal of Cardiology Practice. 2018; $16: 14$.

6. Unger P, Clavel M-A, Lindman BR, Mathieu P, Pibarot P. Pathophysiology and management of multivalvular disease. Nature Reviews Cardiology. 2016; 13(7):429.

7. Rashid M, Parvin T, Ahmed C, Islam M, Monwar M, Karmoker K, et al. Pattern and extent of tricuspid valve involvement in chronic rheumatic heart disease. Mymensingh medical journal: MMJ. 2018; 27(1):120-5.

8. Ahmed R, Kazmi N, Naz F, Malik S, Gillani S. Association of tricuspid regurgitation and severity of mitral stenosis in patients with rheumatic heart disease. Journal of Ayub Medical College Abbottabad. 2016; 28(2):373-5.

9. Rahman M, Das M, Ullah M, Rahman Z, Hossain A, Sayami $L$, et al. A case of severe tricuspid stenosis of rheumatic origin. Cardiovascular Journal. 2011; $3(2): 235-8$

10. Waller BF. Morphological aspects of valvular heart disease: Part I. Current problems in cardiology. 1984; 9(7):1-66.

11. Sultan F, Moustafa SE, Tajik J, Warsame T, Emani U, Alharthi $M$, et al. Rheumatic tricuspid valve disease: An evidence-based systematic overview. J Heart Valve Dis. 2010; 19(3):374-82.

12. Anwar AM, Geleijnse ML, Soliman OI, McGhie JS, Nemes $A$, ten Cate FJ. Evaluation of rheumatic tricuspid valve stenosis by real-time three-dimensional echocardiography. Heart. 2007; 93(3):363-4.
13. Chopra P, Bhatia M. Chronic rheumatic heart disease in India: A reappraisal of pathologic changes. The Journal of heart valve disease. 1992; 1(1):92-101.

14. Nishimura RA, Carabello BA. Hemodynamics in the cardiac catheterization laboratory of the 21st century. Circulation. 2012; 125(17):2138-50.

15. Abbasi AS, Hashmi JA, Robinson Jr RD, Suraya S, Syed SA. Prevalence of heart disease in school children of Karachi. The American journal of cardiology. 1966; 18(4):544-7.

16. Malik SM, Jaffery S, Ahmed S. Prevalence of heart disease in school children of Islamabad. Pakistan Heart Journal. 2012; 14(3).

17. Shaikh MA, Ghori RA, Devrajani BR. Sequelae of chronic rheumatic heart disease among patients at two teaching hospitals in Sindh, Pakistan. JLUMHS. 2006:115.

18. Ilyas M. Rheumatic fever and rheumatic heart disease: The medical menace in the muslim countries. JPMA The Journal of the Pakistan Medical Association. 1982; $32(6): 145-50$

19. Sadiq M, Islam K, Abid R, Latif F, Rehman A, Waheed A, et al. Prevalence of rheumatic heart disease in school children of urban Lahore. Heart. 2009; 95(5):353-7.

20. Asghar U, MT GFN, Amjad M. Prevalence of rheumatic heart disease in different regions of Pakistan. Pak J Med Health Sci. 2017; 11(3):1049-52.

21. Abrar A, Khan S, ur Rehman M, Jan T, Faisal M, Khan $\mathrm{N}$. Frequency of rheumatic heart disease in patients undergoing echocardiography in district Dera Ismail Khan. Gomal Journal of Medical Sciences. 2014; 12(3).

22. Aurakzai HA, Hameed S, Shahbaz A, Gohar S, Qureshi $M$, Khan $H$, et al. Echocardiographic profile of rheumatic heart disease at a tertiary cardiac centre. Journal of Ayub Medical College Abbottabad. 2009; $21(3): 122-6$.

23. Faheem M, Hafizullah M, Gul A, Jan H, Khan MA. Pattern of valvular lesions in rheumatic heart disease. prevalence. 2007; 4:5.

24. Nishimura RA, Otto CM, Bonow RO, Carabello BA, Erwin JP, Guyton RA, et al. 2014 AHA/ACC guideline for the management of patients with valvular heart disease: Executive summary: A report of the American College of Cardiology/American Heart Association Task Force on Practice Guidelines. Journal of the American College of Cardiology. 2014; 63(22):2438-88. 
25. Nishtar S. The national action plan for the prevention and control of non-communicable diseases and health promotion in Pakistan--Prelude and finale. JPMA The Journal of the Pakistan Medical Association. 2004; 54(12 Suppl 3):S1-8.

26. Lawrence JG, Carapetis JR, Griffiths K, Edwards K, Condon JR. Acute rheumatic fever and rheumatic heart disease: incidence and progression in the Northern Territory of Australia, 1997 to 2010. Circulation. 2013;128(5):492-501.

27. Parnaby MG, Carapetis JR. Rheumatic fever in indigenous Australian children. Journal of paediatrics and child health. 2010; 46(9):527-33.

28. Unger P, Clavel MA, Lindman BR, Mathieu P, Pibarot P. Pathophysiology and management of multivalvular disease. Nature Reviews Cardiology. 2016 Jul; 13(7):429.
29. Unger P, Pibarot P, Tribouilloy C. European society of cardiology council on valvular heart disease. Multiple and mixed valvular heart diseases. Circ Cardiovasc Imaging. 2018; 11:e007862.

30. Andell P, Li X, Martinsson A, Andersson C, Stagmo M, Zöller B, Sundquist K, Smith JG. Epidemiology of valvular heart disease in a Swedish nationwide hospital-based register study. Heart. 2017 Nov 1; 103(21):1696-703.

31. Beaton A, Okello E, Lwabi P, Mondo C, McCarter R, Sable C. Echocardiography screening for rheumatic heart disease in Ugandan schoolchildren. Circulation. 2012 Jun 26; 125(25):3127-32.

32. Chockalingam A, Gnanavelu G, Elangovan S, Chockalingam V. Clinical spectrum of chronic rheumatic heart disease in India. The Journal of heart valve disease. 2003 Sep; 12(5):577-81.

33. Maeder MT, Weber L, Buser M, Gerhard M, Haager PK, Maisano F, Rickli H. Pulmonary hypertension in aortic and mitral valve disease. Frontiers in cardiovascular medicine. 2018 May 23; 5:40.

\begin{tabular}{|c|c|c|c|}
\hline \multicolumn{4}{|c|}{ AUTHORSHIP AND CONTRIBUTION DECLARATION } \\
\hline Sr. \# & Author(s) Full Name & Contribution to the paper & Author(s) Signature \\
\hline 1 & Lubna Baqai & 1st Author & \\
\hline 2 & Shazia Rasheed & 2nd Author & Shazin \\
\hline 3 & Naveen Nasim & 3rd Author & NapeenNosin \\
\hline 4 & Irum Jehan Balouch & 4th Author & Fur \\
\hline 5 & Sumiya Gurmani & 5th Author & bummages. \\
\hline 6 & Ghulam Kubra & 6th Author & \\
\hline
\end{tabular}

